\title{
COMPOST FROM MARKET GARBAGE AND THE FEASIBILITY OF REDUCING THE TIME REQUIRED USING AERATION AND LOCALLY ACCLI MATIZEC MICROORGANISMS
}

\author{
${ }^{1} \mathrm{HMM}$ Herath, ${ }^{1} \mathrm{~S}$ Pathinather, ${ }^{2} \mathrm{SC}$ Wijeratne \\ ${ }^{1}$ Department of Civil Engineering, Faculty of Engineering, University of Moratuwa \\ ${ }^{2}$ Department of Botany, Faculty of Applied Sciences, \\ University of Sri Jayewardenepura, Nugegoda.
}

Solid waste collection and disposal is a major problem faced by all local authorities in Sri Lanka.The bulk of the waste, about $83 \%$, is organic materials from vegetable markets and households. The predominant organic matter in waste makes itself ideal for biological treatment process of waste management. The process of composting can be used to convert the waste to a stable "humus like" product commonly known as compost, which could be used as a soil conditioner. This study was conducted using marke garbage as the major ingredient, which contain $70 \%-90 \%$ moisture content and it was mainly directed to use low cost technology. The main objective was to reduce the production time and improve the quality of compost produced with the use of inoculums and aeration.

Six different types of treatments were carried out during the experimental period. The windrow method was used to prepare compost under indoor en ironmental conditions. Vegetable garbage, air-dried grass clippings, saw dust, cow dung and coir dust were used as the raw organic materials. The initial total weight of waste was $250 \mathrm{Kg}$ (by wet weight). The experimental unit was $1.5 \mathrm{~m} \times 1.5 \mathrm{~m} \times 1 \mathrm{~m}$ (length $\mathrm{x}$ width $\mathrm{x}$ height). Two percentages of stabilized compost $(2.5 \%$, $5 \%$ ) were used as the inoculums. Hollow triangular wooden frame was used to facilitate aeration and mixing was carried out once a week.

During the composting process physical changes (temperature, bulk density, changes in distribution of particle sizes), chemical changes ( $\mathrm{pH}$ organic matter, conductivity, $\mathrm{C} / \mathrm{N}$ ratio) and biological changes ( $\mathrm{CO} 2$ evolution, number of total coliform, invertebrates, weed seed viability, germination test) were determined to evaluate the effectiveness of composting process.

The results showed that composting of market garbage using stabilized compost as seeding and aeration helped to produce good compost at the end of two months. The high temperature stage caused the destruction of the pathogenic organisn s (number of coliforms), viability of weed seeds and fly larvae. Weed seed (Ameranthes seeds) lost their viability when exposed to higher temperature $\left(>60^{\circ} \mathrm{C}\right)$ for about three days. The drop in $\mathrm{C} / \mathrm{N}$ ratio is rapid at the initial stages and slows down during maturation stage, whereas the temperature increased and then decreased faster. The decline in temperature and $\mathrm{C} / \mathrm{N}$ ratio are somewhat similar. In all cases, the composting occurred under alkaline conditions and tinally it reached neutral values.

The final weights were approximately half of their or ginal weights and the volume shrieked to $1 / 3$ of their initial volume. The bioassay indicated the level of completeness of composting process and T2, T3 and T4 showed 100\% germination at the end of 2 months.

When composting, high moisture, organic materials under tropical environmental conditions, it is necessary to add bulking material with frequent turting. When composting process is properly operated and managed final product can be obtained in 8 weeks. 